\title{
Evaluating the Therapeutic Success of Keloids Treated With Cryotherapy and Intralesional Corticosteroids Using Noninvasive Objective Measures
}

\author{
Hannah Schwaiger, MD,* Markus Reinholz, MD,* Julian Poetschke, MD, ${ }^{\dagger}$ \\ Thomas Ruzicka, MD,* and Gerd Gauglitz, MD, MMS*
}

BACKGROUND Intralesional corticosteroid injections combined with cryotherapy are considered a first-line therapy for keloids. However, objective evaluation on its efficacy is widely missing.

OBJECTIVE In this study, the authors evaluated the therapeutic benefits of cryotherapy directly followed by intralesional crystalline triamcinolone acetonide injections using ultrasound and a $3 \mathrm{D}$ topographic imaging device.

MATERIALS AND METHODS Fifteen patients with keloids were treated with cryotherapy and intralesional injections of triamcinolone acetonide for a total of 4 times at intervals of 4 weeks. Objective assessment was performed at each visit.

RESULTS After the last treatment, a significant average reduction of scar volume of $34.3 \%$ and an average decrease in scar height of $41.3 \%$ as determined by 3D imaging was observed compared with baseline. Ultrasound revealed an average reduction of scar height of $31.7 \%$ and an average decrease in tissue penetration depth of $37.8 \%$ when compared with baseline measurements.

CONCLUSION Objective measurements of relevant keloid characteristics as height, volume, and penetration depth help in quantifying the therapeutic effect. The observed results confirm that intralesional injections of crystalline triamcinolone acetonide combined with cryotherapy represent a powerful approach to reduce scar height and volume significantly.

The authors have indicated no significant interest with commercial supporters.

$\mathrm{E}$ xcessive scarring is aesthetically disturbing and frequently represents a psychosocial burden for affected patients. ${ }^{1}$ As keloids often go along with pruritus, contractures, and pain, the need for treatment is apparent and not solely based on cosmetic reasoning. ${ }^{2}$ Keloids are benign hyperproliferations of dermal connective tissue. Injury of the deep dermis commonly results in scar formation. The physiologic wound healing cascade consists of inflammation, proliferation, and a remodeling phase. ${ }^{3-5}$ In pathologic scar formation, a prolonged inflammatory phase and some molecular alterations concerning inflammatory pathways are held responsible for excessive scarring. ${ }^{6,7}$ Keloids commonly appear on the upper trunk, and, in contrast to hypertrophic scars, which may show a similar appearance, they exceed the margins of the original wound. Keloids can occur spontaneously but often show a genetic predisposition. Asian or African individuals are more prone to develop keloids. ${ }^{8-11}$ Usually, keloid treatment remains more challenging compared with the therapy of hypertrophic scars because keloids are associated with a high recurrence rate and show no tendency to regress spontaneously. ${ }^{2}$

Over the years, therapeutic approaches to treat excessive scarring have significantly improved. ${ }^{12-14}$ Common therapeutic strategies include silicone gel

*Department of Dermatology and Allergology, Ludwig-Maximilian University, Munich, Germany; ${ }^{+}$Department of Plastic and Hand Surgery, Klinikum St. Georg gGmbH, Leipzig, Germany

(c) 2017 by the American Society for Dermatologic Surgery, Inc. Published by Wolters Kluwer Health, Inc. All rights reserved. ISSN: 1076-0512 • Dermatol Surg 2018;44:635-644 • DOI: 10.1097/DSS.0000000000001427 
sheeting, pressure therapy, radiation, and cryosurgery. ${ }^{15-17}$ New treatment options are intralesional injections of 5-fluorouracil, interferon, and bleomycin for therapy-refractory scars ${ }^{10,18,19}$ as well as nonablative and ablative lasers. ${ }^{20,21}$ In clinical practice, the injection of crystalline glucocorticoids alone or in combination with cryotherapy represents a well-proven therapy. ${ }^{15,22-24}$ Combinational approaches seem to be superior ${ }^{25}$ than respective monotherapies. It is assumed that cryotherapy induces changes in microcirculation and apoptosis of fibroblasts in treated scars. ${ }^{15}$ This procedure results in a localized dermal edema, which facilitates injections into the scar tissue as larger volumes can be applied more easily, thus enhancing the therapeutic effect. ${ }^{13}$ Common side effects of cryotherapy are pain, a prolonged healing time because of the induced blistering, and potential depigmentation. ${ }^{14}$ Triamcinolone acetonide reduces scar thickness by inhibition of the collagen biosynthesis and the proliferation of fibroblasts. Potential side effects include atrophy of the subcutis, the formation of telangiectasia, and pigmentary alterations. ${ }^{2}$

To date, a variety of articles and studies to evaluate different therapeutic approaches for excessive scarring exist. However, most of them use rather subjective measurements to document therapeutic improvements of respective scar therapies. Nevertheless, over the last decade, various studies have highlighted ultrasound as an objective tool to determine changes in scar size..$^{4,26-30}$ More recently, the application of an 3D topographic imaging devices (PRIMOSpico) has also been studied in this context. ${ }^{31,32}$ Based on current data, both tools seem reliable to deliver objective data on changes of physical scar characteristics. ${ }^{27,33}$

Although combination of cryotherapy and intralesional triamcinolone acetonide represents a frequently used technique for the treatment of keloids and has been highlighted as a promising approach in current guidelines, only 4 studies exist on its combination. ${ }^{25,34-36}$ All of them confirmed the effectiveness of intralesional corticosteroids combined with cryotherapy, but none of them applied modern objective measurement methods to assess the therapeutic success. Furthermore, treatment regimens varied, and patients were evaluated before and at the end of treatment, without information on treatment progress. Other studies did not differentiate between hypertrophic scars and keloids. In this study, the authors therefore aimed to evaluate the therapeutic outcome of the guideline-based combination of cryotherapy and corticosteroid injections for keloid treatment using both modern objective imaging solutions.

\section{Materials and Methods}

\section{Patients}

Fifteen patients were included from the outpatient scar clinic ( 7 women, 8 men) aged 18 to 54 years (34.5 \pm 12.5 years) with medium-sized keloids, as defined by common diagnostic criteria, ${ }^{2}$ which had existed for an average of 7.8 years ( \pm 5.3 years). Fitzpatrick skin types ranged from II to IV. Keloids either after trauma, surgery, acne, or by spontaneous formation were located mainly on the upper trunk (Table 1). Most patients had treatments in the past, which mainly included moisturizers such as silicones, cryotherapy alone, or laser, which were either unsuccessful or led to a regress of keloid formation. The patients were enrolled after approval by the Ethics Committee of the Ludwig-Maximilian University, and written informed consent from each patient was obtained. Exclusion criteria were pregnancy, intralesional injections of corticosteroids during the last 6 months, chronic diseases such as diabetes or coagulopathies, and participation in other studies.

Patients were treated 4 times with cryotherapy directly followed by intralesional injections of triamcinolone acetonide into each scar at monthly intervals. Standardization of injection techniques was based on the authors' clinical settings and obtained by using the same drug, same needle size (27 Gauge), and same brand of Luer-lock syringes for injections. Keloids were injected by the same experienced physician at each visit. Injection volumes were depending on the size of the keloid and were carefully documented; a visible blanching of the keloid tissue was considered as end points of injections. In accordance with other studies, national and international guidelines 
TABLE 1. Patient Characteristics

\begin{tabular}{llllllllc} 
Patient & Sex & Age & Skin Type & Etiology & \multicolumn{1}{c}{ Location } & $\begin{array}{c}\text { Scar } \\
\text { Age }\end{array}$ & $\begin{array}{c}\text { Family History of } \\
\text { Keloids }\end{array}$ & $\begin{array}{c}\text { Previous } \\
\text { Treatment }\end{array}$ \\
\hline 1 & M & 21 & II & Trauma & $\begin{array}{c}\text { Shoulder/back/ } \\
\text { breast }\end{array}$ & 1.5 & None \\
2 & M & 48 & III & Surgery & Breast & 4 & None \\
3 & F & 48 & II & Surgery & Breast & 10 & - & Moisturizing, \\
silicone
\end{tabular}

treatment was initiated with triamcinolone acetonide concentrations of $10 \mathrm{mg} / \mathrm{mL}$, which were increased up to $40 \mathrm{mg} / \mathrm{mL}$ at subsequent visits. ${ }^{34,37}$ Directly before injection, cryotherapy was applied with liquid nitrogen spray for 10 seconds and the exact same procedure was repeated after 1 minute. Ultrasound and 3D topographic imaging measurements were performed directly before the respective treatment by the same investigator.

\section{D Topographic Imaging Device: Phase Shift Rapid In Vivo Measurement of Skin (PRIMOSpico)}

To provide 3-dimensional and high-resolution images of the scars, the PRIMOSpico system (GFMesstechnik, Teltow, Germany) was used. The device is commonly applied to measure wrinkles. ${ }^{26,27,38}$ Furthermore, it is highly suitable to assess pathologic scarring. ${ }^{32,33}$ Using micromirrors, this 3D topographic imaging device projects a stripe pattern with sinusoidal gray levels, which is captured by a CCD camera. Measuring the gray levels and displacement of this stripe pattern creates a detailed and color-coded height map of the measured surface. These height maps were used to analyze scar height and volume.

\section{Sonography}

Scars were assessed during each visit by using a highresolution B-image sonogram. To ensure a good penetration depth into the scar combined with a high resolution, a 11-MHz receiving transducer was used in combination with the Logiq P6 Pro (GE Healthcare, Solingen, Germany) and a sufficient amount of ultrasound gel was applied to avoid pressure on the scar, which may influence measurement. According to the manufacturer, this configuration yields a skin penetration depth of up to $40 \mathrm{~mm}$ and a lateral resolution of about $158 \mu \mathrm{m}$. Sonography was used to analyze scar elevation and cutaneous penetration.

\section{Digital Photography}

Digital photography was used to document the therapeutic success. A professional in-house photographer took photos during each visit after obtaining additional written informed consent for this procedure from each patient. Photography was not standardized between visits within the study limitations section.

\section{Data Analysis}

Statistical analyses were performed using the GraphPad Prism 5 Software (GraphPad Software, 
Inc., La Jolla, CA). The data were first analyzed for Gaussian distribution using the D'Agostino and Pearson omnibus normality test. After establishing Gaussian distribution of data, the repeated-measures ANOVA was applied to calculate statistical significance of the results, which were displayed as mean \pm SD. To compare the results of each visit in detail, Bonferroni's Multiple Comparison Test was used. The significance level was set at $\alpha=0.05$.

\section{Results}

The authors evaluated the therapeutic progress of triamcinolone acetonide injections in combination with cryotherapy in a total of 15 patients during each visit directly before the respective treatment. In addition, adverse events and side effects were documented: 8 patients developed telangiectasia, 4 of them showed pigmentation disorders such as reddish brown discoloration of the keloid, and one suffered from temporary ulceration after the fourth injection. The obtained results regarding injected amount of triamcinolone acetonide were evaluated for each visit

TABLE 2. Evaluation of Injected Volumes of Triamcinolone Acetonide and Absolute Measurement Results of Scar Height, Volume, and Penetration Depth

\begin{tabular}{|c|c|}
\hline & $\begin{array}{l}\text { Absolute } \\
\text { Results }\end{array}$ \\
\hline \multicolumn{2}{|l|}{$\begin{array}{l}\text { Injected amount of TAC in } n=15 \\
\text { keloids }\end{array}$} \\
\hline At Visit I: 10-20 mg/mL & Visit I: $0.9 \pm 0.6 \mathrm{~mL}$ \\
\hline At Visit II: $10-20-40 \mathrm{mg} / \mathrm{mL}$ & Visit II: $0.9 \pm 0.7 \mathrm{~mL}$ \\
\hline At Visit III + IV: $20-40 \mathrm{mg} / \mathrm{mL}$ & $\begin{array}{l}\text { Visit III: } 0.4 \pm 0.3 \mathrm{~mL} \\
\text { Visit IV: } 0.5 \pm 0.3 \mathrm{~mL}\end{array}$ \\
\hline \multicolumn{2}{|l|}{ Average height $\pm \mathrm{SD}$} \\
\hline Before & $3.2 \pm 1.2 \mathrm{~mm}$ \\
\hline After & $2.2 \pm 1.2 \mathrm{~mm}$ \\
\hline \multicolumn{2}{|l|}{ Average volume $\pm \mathrm{SD}$} \\
\hline Before & $737 \pm 417 \mathrm{~mm}^{3}$ \\
\hline After & $443 \pm 345 \mathrm{~mm}^{3}$ \\
\hline \multicolumn{2}{|l|}{ Average embossment $\pm S D$} \\
\hline Before & $2.5 \pm 1.5 \mathrm{~mm}$ \\
\hline After & $1.7 \pm 1.3 \mathrm{~mm}$ \\
\hline \multicolumn{2}{|c|}{ Average penetration depth \pm SD } \\
\hline Before & $2.0 \pm 1.3 \mathrm{~mm}$ \\
\hline After & $1.4 \pm 1.2 \mathrm{~mm}$ \\
\hline
\end{tabular}

TAC, triamcinolone acetonide.
(Table 2). For the first and the second injection, the amount of triamcinolone acetonide averaged $0.9 \mathrm{~mL}$ $( \pm 0.6 \mathrm{~mL}$ for the first injection and $\pm 0.7 \mathrm{~mL}$ for the second injection) for each keloid and decreased to $0.4 \mathrm{~mL}( \pm 0.3 \mathrm{~mL}$ ) of injected triamcinolone acetonide at the third visit. At Visit 4, an average amount of $0.5 \mathrm{~mL}( \pm 0.3 \mathrm{~mL})$ triamcinolone acetonide was injected. The decreased amount of crystalline corticosteroid throughout the treatment session resulted from the reduced scar volume.

\section{Digital Photography}

Visual assessment of photographs taken before and after treatment showed clear improvement of scar volume and circumference objectively interpreted by a blinded rater (Figure 1).

\section{D Topographic Imaging Device}

In matching mode, a program of the used 3D topographic imaging device, a comparison of the scar before (Figure 2A) and after treatment (Figure 2B) is possible. A highly significant $(p<.0001)$ reduction of surface height after 4 treatment sessions could be observed (Figure 3A). After the first treatment and before the second intervention, the scar elevation was reduced significantly by $18.3 \%( \pm 15.1 \%)(p=.0143)$ compared with baseline. Subsequent documentation showed a reduction of $29.9 \%( \pm 17.9 \%)(p=.2258)$ after the second, $37.8 \%( \pm 19.9 \%)(p=.3391)$ after the third, and $41.3 \%( \pm 20.6 \%)(p=.2075)$ after the fourth treatment session compared with baseline (Figure 3B). These results were proportional to the calculated loss of volume of the scar during treatment with triamcinolone acetonide injections (Figure 3C). After the first injection, the average volume was reduced by $13.1 \%( \pm 10.3 \%)(p=.017)$, after the second by $21.7 \%( \pm 14.0 \%)(p=.4602)$, and after the third injection by $30.5 \%( \pm 16.9 \%)(p=.5011)$. By the fourth visit, the relative decrease of height and volume was $34.3 \%( \pm 18.0 \%)(p=.4799)$ compared with baseline (Figure 3D).

\section{Sonography}

Ultrasound measurements demonstrated a significant reduction of scar elevation, penetration depth and 

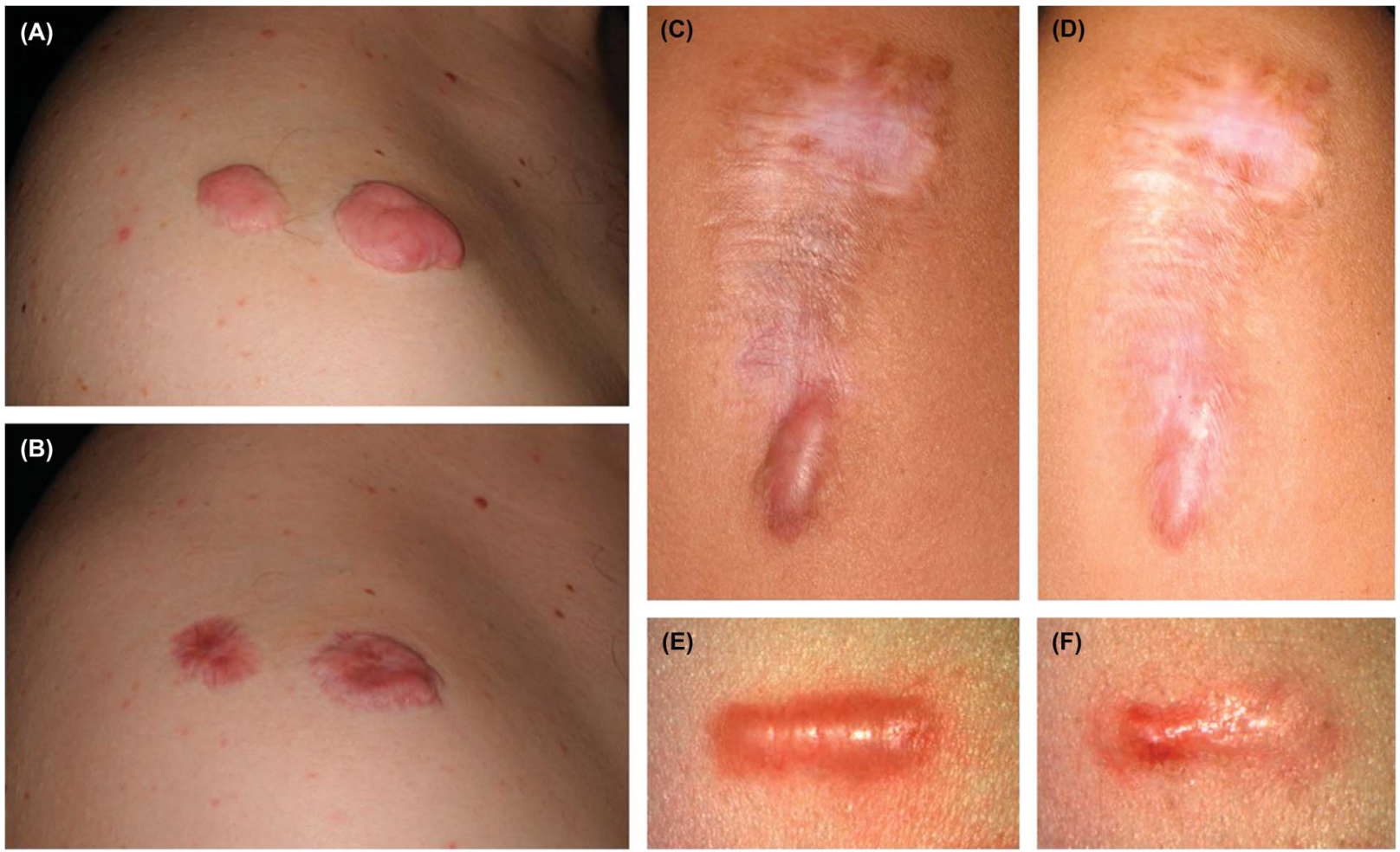

Figure 1. Digital photography of Patient 15 (A and B), Patient 5 (C and D), and Patient 13 (E and F) with keloid before (A, C, and $E$ ) and after (B, D, and F) 4 injections of triamcinolone acetonide in combination with cryotherapy.

volume, as well as a reduction of echo-poor areas corresponding to collagen-rich scar tissue (Figure 4A). As treatment progressed, more echo-rich reflections became visible in the sonogram indicating a transformation into more homogeneous scar tissue (Figure 4B). By sonography, a decrease of scar height (Figure 5A) and intracutaneous infiltration
(Figure 5C) could be demonstrated. After one treatment, an average reduction of scar height of $12.9 \%$ $( \pm 14.8 \%)(p=.0134)$ was observed, after 2 injections $19.8 \%( \pm 15.9 \%)(p=.0489)$, after 3 treatments $26.7 \%( \pm 18.6 \%)(p=.1993)$, and after 4 injections $31.7 \%( \pm 19.9 \%)(p=.3992)$ compared with baseline (Figure 5B). The reduction in subepidermal depth of
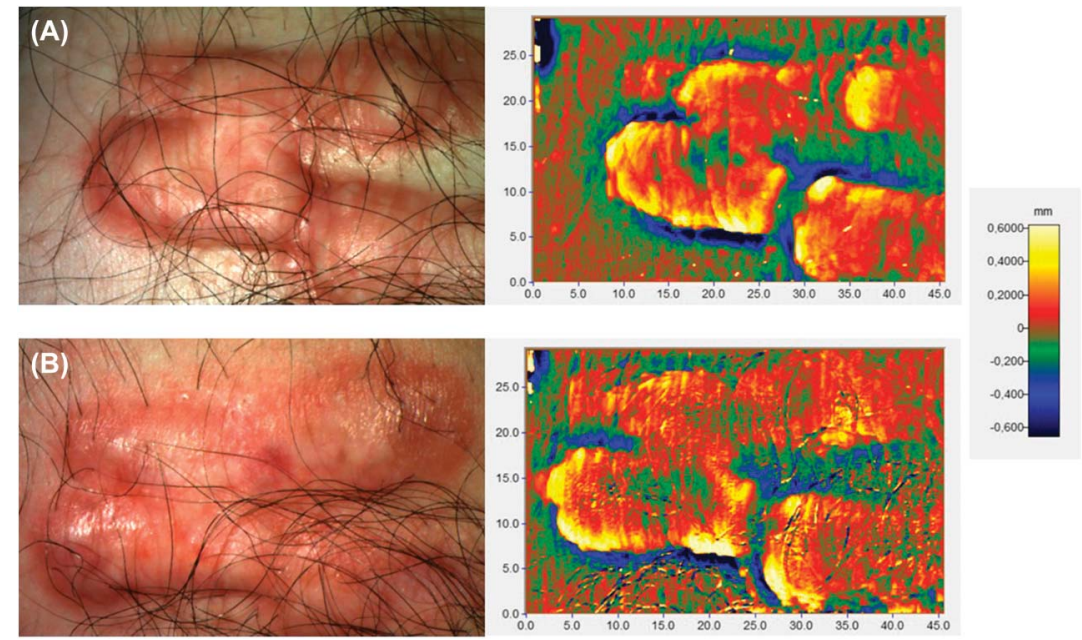

Figure 2. The skin-tone and color-height-encoded images were taken with the 3D topographic imaging device PRIMOSpico using the matching program mode. Patient 2-native scar $(A)$-was treated 4 times with cryotherapy and triamcinolone acetonide injections (B). 

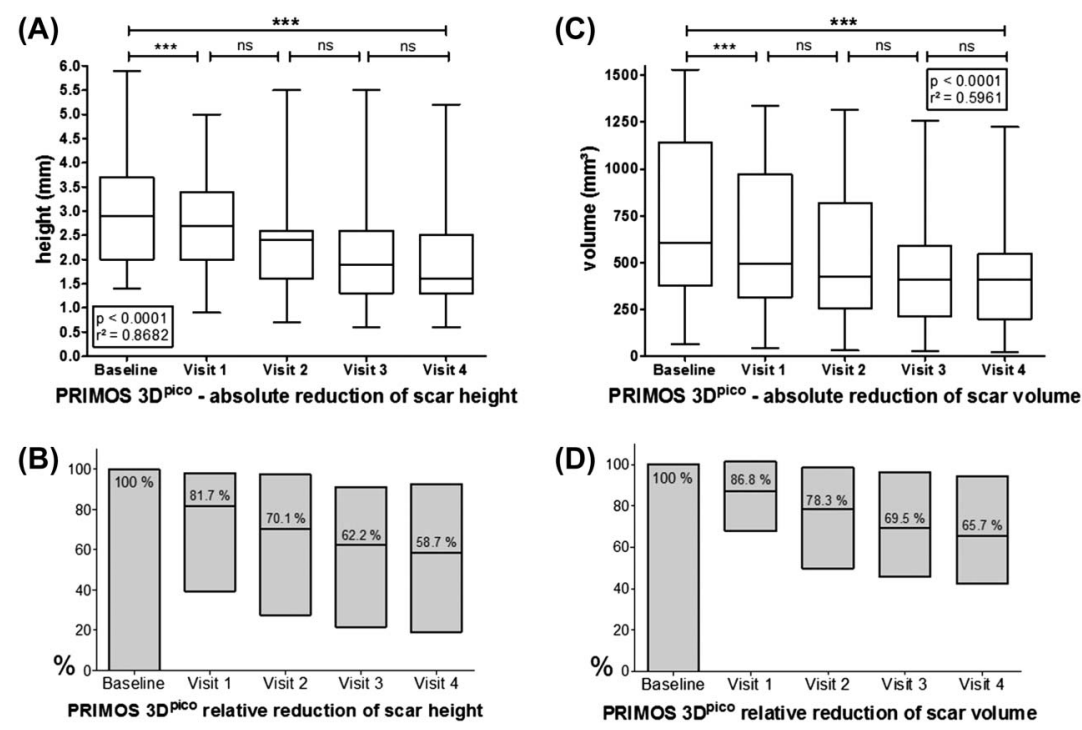

Figure 3. Absolute reduction of surface height $(A)$ and volume $(C)$ as well as the relative results of the reduction of scar height (B) and volume (D) as measured with PRIMOS pico.

the scar after one injection was $15.5 \%( \pm 12.0 \%)$ $(p=.0018)$ and after 2 interventions $25.0 \%( \pm 15.4 \%)$ $(p=.1438)$. An average reduction of $33.2 \%( \pm 17.4 \%)$ $(p=.1466)$ after 3 and of $37.8 \%( \pm 16.7 \%)(p=.1723)$ after 4 injections could be observed (Figure 5D).

\section{Discussion}

In this study, the authors aimed to objectively evaluate treatment success of the guideline-based combinational therapy of cryotherapy and triamcinolone acetonide injections ${ }^{2,14}$ for the treatment of keloids by using a 3D topographic imaging device and ultrasound. Based on objective measurements, a significant average reduction of scar volume of $34.3 \%$ and an average decrease in scar height of $41.3 \%$ as determined by $3 \mathrm{D}$ imaging was observed after a total of 4 treatment sessions compared with baseline. Ultrasound revealed an average reduction of scar height of $31.7 \%$ and an average decrease in tissue penetration depth of $37.8 \%$ when compared with baseline measurements. More specifically, 5 of 15 patients reached an average reduction of scar height and volume of $50 \%$ or more after 4 treatment series. An average reduction between $50 \%$ and $20 \%$ could be observed in 5 patients. The remaining 5 patients did not achieve a sufficient reduction of volume and height and defined as average reduction by $20 \%$ or less after 4 injections of triamcinolone acetonide combined with cryotherapy. Based on their observation, a reduction of scar height by $20 \%$ or less after 2 treatment periods constitutes an adequate objective criterion to define resistance to therapy. Treatments within their study were tolerated relatively well although intralesional
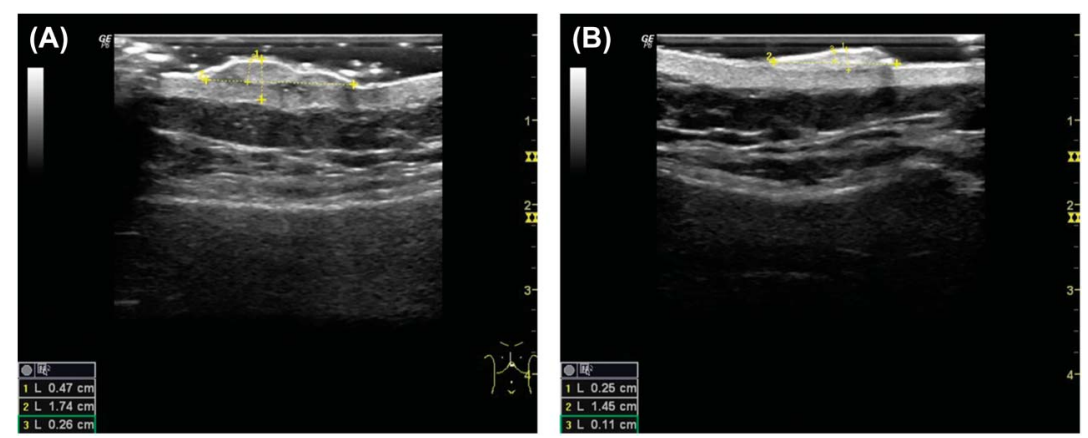

Figure 4. Ultrasound images of Patient 9 in measuring mode before (A) and after (B) treatment. Clearly visible in the reduction of embossment and penetration depth. In addition, a decrease of the darker areas before therapy to a more homogeneous scar tissue after 4 injections of triamcinolone acetonide and cryotherapy is apparent. 
(A)
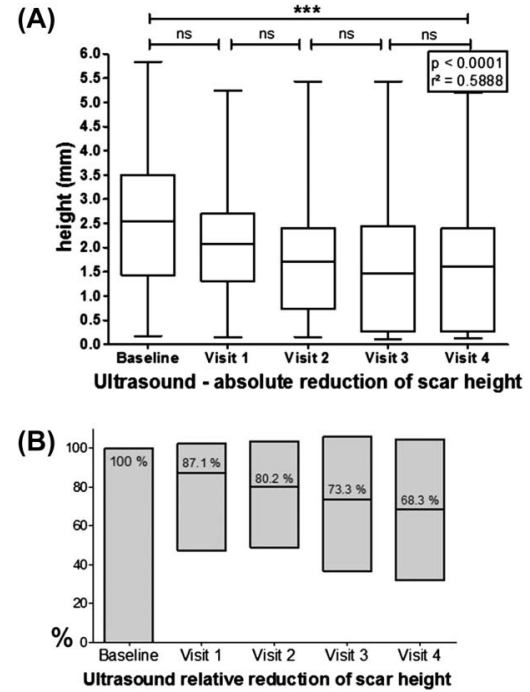

(C)

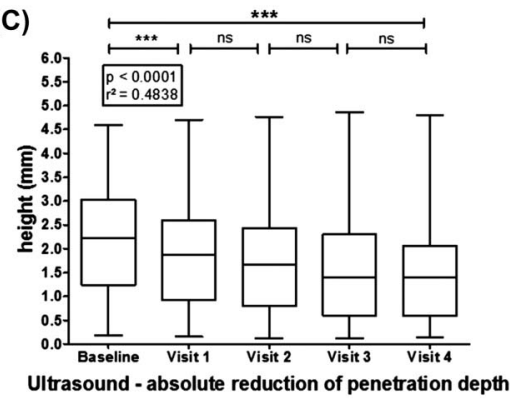

(D)

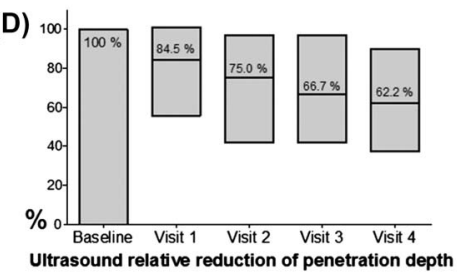

Figure 5. Evaluation of the absolute reduction of scar height $(A)$ and penetration depth $(C)$ measured with high-resolution $\mathrm{B}$-image sonogram. The authors also observed relative results of the reduction of scar height (B) and penetration depth into the skin (D).

corticosteroid injections have shown side effects in up to $63 \%$ of patients. ${ }^{11}$ Adverse events in their setting mostly included formation of telangiectasia $(n=8)$, which may be easily improved by pulsed dye lasers or intense pulsed light.

In depth, assessment of scar therapy is crucial to prevent the implementation of treatment regimen with a considerable risk of side effects, disproportionate to the achieved therapeutic success.

Intralesional corticosteroid injections with supplementary cryotherapy are first-line therapy for the treatment of keloids. ${ }^{2,39}$ In 1977, the combination of corticosteroids and cryosurgery was introduced and detailed information on the method provided. ${ }^{36}$ Despite the lack of objective parameters, the promising results led to the establishment of this method. Injections are recommended for at least 3 courses $^{25}$ or until complete flattening of the scar is reached. A maximum of 8 injections has been proposed..$^{37,40} \mathrm{An}$ interindividual controlled study with 10 patients using calipers and digital photography was performed to determine the effect of cryotherapy and corticosteroid injections in keloids. ${ }^{25}$ A more objective assessment method was used in a study of 33 patients $^{35}$ : they took a wax pattern of alginate impressions of each keloid to observe changes in volume and surface of the keloids. Patients were treated only once with either cryotherapy or corticosteroid injections alone or their combination. The results of combination therapy were significantly better than either method alone, so the authors proposed synergistic effect of cryotherapy and intralesional triamcinolone acetonide. The latest study on 21 patients was published in 2008 and compared the therapeutic outcome of either cryotherapy or corticosteroid injections into the keloid alone with the combination of both. ${ }^{34} \mathrm{~A}$ visual analog scale was used to evaluate the treatment results, which concluded that the combination therapy was superior.

Current guidelines for scar therapy ${ }^{2,13}$ mention a response rate, which varies between $50 \%$ and $100 \%$ and a recurrence rate between $9 \%$ and $50 \%$ according to meta-analysis. ${ }^{41-43}$ These data are based on studies, which applied different treatment regimens and diverse evaluation methods-neither objective measurement methods have been applied nor the combination of cryotherapy and corticosteroid injections into the keloid has been evaluated. The 4 studies, which observed the therapy results of corticosteroid injections alone, were performed in the 1970s or before. ${ }^{42-45}$ Newer study approaches have not yet been included in current publications. Also, some studies did not differentiate between keloids and hypertrophic scars. As the latter commonly regress spontaneously, ${ }^{2}$ a definite conclusion about the recurrence rate of enhanced scar formation cannot be made. The wide 
fluctuation of response and recurrence rates is not only due to the various study approaches but also illustrates that every scar requires an individualized treatment. A standard approach still does not exist. The updated international guidelines for scar therapy, therefore, favor a combination approach with multiple modalities. ${ }^{46}$

With modern 3D topographic imaging device height, volume and surface of the scar can be objectively documented and compared with a baseline measurement. The 3D topographic imaging devices as the PRIMOSpico have already provided solid data and valid results in studies evaluating the therapy of hypertrophic scars, keloids, acne scars, and striae distensae. ${ }^{21,26,31,32,38}$ The various presentation modes are helpful for the 3-dimensional demonstration of the treatment progress. The safe and easy handling makes it a promising tool in clinical scar examination. It is well-suitable for small to medium scars, but in case of extended keloid formation, the 3D imaging unit's field of view may be too small to capture the entire scar. Another disadvantage is its inability to measure skin Types V and VI. As keloids occur more often in Asian or African individuals ${ }^{9}$ who present mainly with darker skin types such as IV to VI according to Fitzpatrick, ${ }^{47}$ ultrasound measurement should be preferred.

Sonography represents a frequently used noninvasive observation tool in the treatment of pathologic scars. ${ }^{4,26-29}$ In dermatological research, high frequency ultrasound with $7.5 \mathrm{MHz}$ and above is used. It offers a sufficient penetration depth as well as high resolution and thereby achieves reliable measurement results in scar assessment. In contrast to 3D topographic imaging devices, ultrasound enables the assessment of scar height and penetration depth but not of the volume or surface. However, ultrasound is available in nearly every clinical institution. This might facilitate its more frequent use compared with other devices.

Based on their study data, both applied objective measurement methods can be recommended as highly suitable for the therapeutic assessment of pathologic scars. For an overall therapeutic assessment, however, standardized questionnaires may be helpful by adding additional relevant parameters to the evaluation ${ }^{33,48,49}$ because successful scar treatments also include the reduction of scar-associated symptoms such as pain, contractures, and pruritus. Established questionnaires such as the Patient and Observer Scar Assessment Scale or the Dermatology Life Quality Index cover important items of augmented scar formation and may therefore be applied for additional assessment of scar therapy. ${ }^{1,49}$

Limitations of their study include the relatively small number of included patients, the lack of follow-ups, and certain shortcomings in the standardization of the injection technique itself.

\section{Conclusion}

As corticosteroid injections and cryotherapy are the mainstay of therapy for hypertrophic scars and keloids, evaluating the evidence of this treatment approach is required. Here, the authors could demonstrate that ultrasound assessment along with noninvasive in vivo 3D topographic imaging measurements could objectively confirm the clinically observed efficacy of combined cryotherapy and intralesional injection of corticosteroids for the treatment of keloids if the physician is considering potential side effects such as neovesselfomation and pigmentary changes.

Because of its sensitivity, these objective measures may be useful in identifying responders from nonresponders earlier than conventional assessments and may thus represent promising tools in future scar assessments.

\section{References}

1. Reinholz M, Poetschke J, Schwaiger H, Epple A, et al. The dermatology life quality index as a means to assess life quality in patients with different scar types. J Eur Acad Dermatol Venereol 2015;29:2112-9.

2. Nast A, Eming S, Fluhr J, Fritz K, et al. German S2k guidelines for the therapy of pathological scars (hypertrophic scars and keloids). J Dtsch Dermatol Ges 2012;10:747-62.

3. Chike-Obi CJ, Cole PD, Brissett AE. Keloids: pathogenesis, clinical features, and management. Semin Plast Surg 2009;23:178-84.

4. Lumenta DB, Siepmann E, Kamolz LP. Internet-based survey on current practice for evaluation, prevention, and treatment of scars, 
hypertrophic scars, and keloids. Wound Repair Regen 2014;22: 483-91.

5. Gantwerker EA, Hom DB. Skin: histology and physiology of wound healing. Facial Plast Surg Clin North Am 2011;19:441-53.

6. Al-Attar A, Mess S, Thomassen JM, Kauffman CL, et al. Keloid pathogenesis and treatment. Plast Reconstr Surg 2006;117:286-300.

7. Berman B, Maderal A, Raphael B. Keloids and hypertrophic scars: pathophysiology, classification, and treatment. Dermatol Surg 2016;43:3-18.

8. Shih B, Bayat A. Genetics of keloid scarring. Arch Dermatol Res 2010; 302:319-39.

9. Davis SA, Feldman SR, McMichael AJ. Management of keloids in the United States, 1990-2009: an analysis of the national ambulatory medical care survey. Dermatol Surg 2013;39:988-94.

10. Payapvipapong K, Niumpradit N, Piriyanand C, Buranaphalin S, et al. The treatment of keloids and hypertrophic scars with intralesional bleomycin in skin of color. J Cosmet Dermatol 2015;14:83-90.

11. Mustoe TA, Cooter RD, Gold MH, Hobbs FD, et al. International clinical recommendations on scar management. Plast Reconstr Surg 2002;110:560-71.

12. Arno AI, Gauglitz GG, Barret JP, Jeschke MG. New molecular medicine-based scar management strategies. Burns 2014;40:539-51.

13. Gauglitz GG. Management of keloids and hypertrophic scars: current and emerging options. Clin Cosmet Investig Dermatol 2013;6:103-14.

14. Gold MH, Berman B, Clementoni MT, Gauglitz GG, et al. Updated international clinical recommendations on scar management: part 1-evaluating the evidence. Dermatol Surg 2014;40:817-24.

15. Karagoz H, Yuksel F, Ulkur E, Evinc R. Comparison of efficacy of silicone gel, silicone gel sheeting, and topical onion extract including heparin and allantoin for the treatment of postburn hypertrophic scars. Burns 2009;35:1097-103.

16. Beuth J, Hunzelmann N, Van Leendert R, Basten R, et al. Safety and efficacy of local administration of contractubex to hypertrophic scars in comparison to corticosteroid treatment. Results of a multicenter, comparative epidemiological cohort study in Germany. In Vivo 2006; 20:277-83.

17. Candy LH, Cecilia LT, Ping ZY. Effect of different pressure magnitudes on hypertrophic scar in a Chinese population. Burns 2010;36:1234-41.

18. Camacho-Martinez FM, Rey ER, Serrano FC, Wagner A. Results of a combination of bleomycin and triamcinolone acetonide in the treatment of keloids and hypertrophic scars. An Bras Dermatol 2013; 88:387-94.

19. Wilson AM. Eradication of keloids: surgical excision followed by a single injection of intralesional 5-fluorouracil and botulinum toxin. Can J Plast Surg 2013;21:87-91.

20. Kim DH, Ryu HJ, Choi JE, Ahn HH, et al. A comparison of the scar prevention effect between carbon dioxide fractional laser and pulsed dye laser in surgical scars. Dermatol Surg 2014;40:973-8.

21. Chapas AM, Brightman L, Sukal S, Hale E, et al. Successful treatment of acneiform scarring with $\mathrm{CO} 2$ ablative fractional resurfacing. Lasers Surg Med 2008;40:381-6.

22. Atiyeh BS. Nonsurgical management of hypertrophic scars: evidencebased therapies, standard practices, and emerging methods. Aesthetic Plast Surg 2007;31:468-92; discussion 493-464.

23. Khan MA, Bashir MM, Khan FA. Intralesional triamcinolone alone and in combination with 5-fluorouracil for the treatment of keloid and hypertrophic scars. J Pak Med Assoc 2014;64:1003-7.

24. Davison SP, Dayan JH, Clemens MW, Sonni S, et al. Efficacy of intralesional 5-fluorouracil and triamcinolone in the treatment of keloids. Aesthet Surg J 2009;29:40-6.
25. Yosipovitch G, Widijanti Sugeng M, Goon A, Chan YH, et al. A comparison of the combined effect of cryotherapy and corticosteroid injections versus corticosteroids and cryotherapy alone on keloids: a controlled study. J Dermatolog Treat 2001;12:87-90.

26. Bleve M, Capra P, Pavanetto F, Perugini P. Ultrasound and 3D skin imaging: methods to evaluate efficacy of striae distensae treatment. Dermatol Res Pract 2012;2012:673706.

27. Perry DM, McGrouther DA, Bayat A. Current tools for noninvasive objective assessment of skin scars. Plast Reconstr Surg 2010;126:912-23.

28. Cheng W, Saing H, Zhou H, Han Y, et al. Ultrasound assessment of scald scars in Asian children receiving pressure garment therapy. J Pediatr Surg 2001;36:466-9.

29. Fraccalvieri M, Sarno A, Gasperini S, Zingarelli E, et al. Can single use negative pressure wound therapy be an alternative method to manage keloid scarring? A preliminary report of a clinical and ultrasound/ colour-power-doppler study. Int Wound J 2013;10:340-4.

30. Acosta S, Ureta E, Yanez R, Oliva N, et al. Effectiveness of intralesional triamcinolone in the treatment of keloids in children. Pediatr Dermatol 2016;33:75-9.

31. Friedman PM, Skover GR, Payonk G, Geronemus RG. Quantitative evaluation of nonablative laser technology. Semin Cutan Med Surg 2002;21:266-73.

32. Gauglitz GG, Bureik D, Dombrowski Y, Pavicic, et al. Botulinum toxin A for the treatment of keloids. Skin Pharmacol Physiol 2012;25:313-8.

33. Poetschke J, Schwaiger H, Gauglitz GG. Current and emerging options for documenting scars and evaluating therapeutic progress. Dermatol Surg 2016;43:25-36.

34. Sharma S, Bhanot A, Kaur A, Dewan SP. Role of liquid nitrogen alone compared with combination of liquid nitrogen and intralesional triamcinolone acetonide in treatment of small keloids. J Cosmet Dermatol 2007;6:258-61.

35. Anchlia S, Rao KS, Bonanthaya K, Vohra D. Keloidoscope: in search for the ideal treatment of keloids. J Maxillofac Oral Surg 2009;8:366-70.

36. Ceilley RI, Babin RW. The combined use of cryosurgery and intralesional injections of suspensions of fluorinated adrenocorticosteroids for reducing keloids and hypertrophic scars. J Dermatol Surg Oncol 1979;5:54-6.

37. Trisliana Perdanasari A, Lazzeri D, Su W, Xi W, et al. Recent developments in the use of intralesional injections keloid treatment. Arch Plast Surg 2014;41:620-9.

38. Bloemen MC, van Gerven MS, van der Wal MB, Verhaegen PD, et al. An objective device for measuring surface roughness of skin and scars. J Am Acad Dermatol 2011;64:706-15.

39. Block L, Gosain A, King TW. Emerging therapies for scar prevention. Adv Wound Care (New Rochelle) 2015;4:607-14.

40. Ahuja RB, Chatterjee P. Comparative efficacy of intralesional verapamil hydrochloride and triamcinolone acetonide in hypertrophic scars and keloids. Burns 2014;40:583-8.

41. Robles DT, Moore E, Draznin M, Berg D. Keloids: pathophysiology and management. Dermatol Online J 2007;13:9.

42. Kiil J. Keloids treated with topical injections of triamcinolone acetonide (kenalog). Immediate and long-term results. Scand J Plast Reconstr Surg 1977;11:169-72.

43. Griffith BH, Monroe CW, McKinney P. A follow-up study on the treatment of keloids with triamicinolone acetonide. Plast Reconstr Surg 1970;46:145-50.

44. Ketchum LD, Robinson DW, Masters FW. Follow-up on treatment of hypertrophic scars and keloids with triamcinolone. Plast Reconstr Surg 1971;48:256-9. 
45. Griffith BH. The treatment of keloids with triamcinolone acetonide. Plast Reconstr Surg 1966;38:202-8.

46. Gold MH, McGuire M, Mustoe TA, Pusic A, et al. Updated international clinical recommendations on scar management: part 2-algorithms for scar prevention and treatment. Dermatol Surg 2014; 40:825-31.

47. Roberts WE. Skin type classification systems old and new. Dermatol Clin 2009;27:529-33. viii.

48. Reinholz M, Schwaiger H, Poetschke J, Epple A, et al. Objective and subjective treatment evaluation of scars using optical coherence tomography, sonography, photography, and standardised questionnaires. Eur J Dermatol 2016;26:599-608.

49. Poetschke J, Reinholz M, Schwaiger H, Epple A, et al. DLQI and POSAS Scores in keloid patients. Facial Plast Surg 2016;32:289-95.

Address correspondence and reprint requests to: Hannah Schwaiger, MD, Department of Dermatology and Allergology, Ludwig-Maximilian University, Frauenlobstr. 9-11, 80337 Munich, Germany, or e-mail: hannah.schwaiger@web.de 